\title{
Structural and functional markers of health depending on lifestyle in elderly women from Poland
}

\author{
Anna Skrzek' \\ Zofia Ignasiak ${ }^{2}$ \\ Teresa Sławińska² \\ Jarosław Domaradzki² \\ Jarosław Fugiel ${ }^{2}$ \\ Anna Sebastjan ${ }^{2}$ \\ Krystyna Rożek' \\ 'Faculty of Physiotherapy, ${ }^{2}$ Faculty \\ of Physical Education, University \\ School of Physical Education \\ in Wroclaw, Wroclaw, Poland
}

This article was published in the following Dove Press journal:

Clinical Interventions in Aging

2I April 2015

Number of times this article has been viewed

Objective: To comparatively analyze the rate and magnitude of age-related changes between two groups of elderly women with different lifestyles living in Poland: women attending a University of the Third Age (active lifestyle) and less-active peers not involved in any seniors association.

Methods: The study was conducted in 2010-2012. The study design was approved by the Senate Ethics Committee for Scientific Research of the University School of Physical Education. In total, 417 women were recruited. Basic somatic characteristics, body composition, bone mineral density, physical fitness, respiratory function, postural stability, and body posture were measured. Regression analysis and Student's $t$-tests for independent samples were calculated. Results and conclusion: The best results among the tests assessing functional biological markers of health were found in the group of elderly women attending a University of the Third Age. The rate of change was larger in the group of seniors leading a less-active lifestyle, indicating the important role of a preventive gerontological approach and the participation of seniors in programs that accentuate the need for physical activity.

Keywords: age-related changes, bone mineral density, markers of health, lifestyle, elderly women

\section{Introduction}

Although multidisciplinary gerontological research has confirmed that senescence is inevitable, life expectancy can be determined by not only biological but also environmental factors such as lifestyle. However, the process of aging and the period of old age is still the least understood stage of human development. It is a highly diversified process that differs greatly from individual to individual and depends on many factors. For this reason, research on its causes still poses numerous challenges.

A review of the available literature indicates that an active lifestyle is one of the most significant factors affecting the health, independence, and quality of life of the elderly.

The most commonly analyzed component of a healthy lifestyle is physical activity. Lampinen et $\mathrm{al}^{1}$ reported that regular exercise can be considered to be a preventive measure of aging as well as have a positive effect on mental performance. The impact of physical activity on cell-level processes was analyzed by Cherkas et $\mathrm{al}^{2}$ who found that leukocyte telomere length is dependent on physical activity level. Chipperfield ${ }^{3}$ showed that physical activity declines with advancing age, demonstrating the beneficial effects of daily physical activity in increasing life expectancy.

No less important than an active lifestyle is maintaining intellectual well-being, as it also has been connected with a high quality of life during old age. In this regard,
Correspondence: Jarosław Fugie Faculty of Physical Education, University School of Physical Education in Wroclaw, al Paderewskiego 35, 5I-6|2 Wroclaw, Poland Email jaroslaw.fugiel@awf.wroc.pl 
some researchers have indicated the leading role of continuing education among aging adults. ${ }^{4}$ Mental agility can be improved in a number of ways, but almost any activity that involves increased mental effort is sufficient. The inclusion of the elderly in a continuing education system can have a number of positive effects, including nurturing self-development and allowing them to meet personal goals, preparing them to play an active role in various spheres of social life, preventing feelings of isolation and marginalization, and introducing them to changes in science, technology, and society.

Arai et $\mathrm{al}^{5}$ examined the relationship between physical activity and interpersonal relationships with the incidence of depression. They observed that, despite maintaining a similar level of physical activity, older people who were socially inactive were more often depressed. That loneliness is a potential risk factor for depression in the elderly, and this was also determined by Paul et al, ${ }^{6}$ Miller et al, ${ }^{7}$ and Adams et al. ${ }^{8}$ The importance of interpersonal relationships on overall well-being was also analyzed in many other studies. ${ }^{9-11}$

Many studies have concurred that older people are motivated and want to "actively age". This "active aging" concept was officially adopted by the World Health Organization ${ }^{12,13}$ in 1990, which emphasized the desire of seniors to participate in social, cultural, and physical activities. It defined the rights and responsibilities of older persons and provided a framework for the development of programs aimed at improving their quality of life. It is these types of programs that have been enacted by U3As in many countries around the world, including Finland, ${ }^{14}$ Italy, ${ }^{15}$ Australia, ${ }^{16}$ Taiwan, ${ }^{17}$ Japan and Canada, ${ }^{18}$ and Poland. ${ }^{19,20}$

A great deal of the literature has considered an active lifestyle along with physical activity to be important predictors of the quality of life of older people. ${ }^{21-23}$ Nonetheless, in order for any kind of health promotion program to be successful when put into practice, it is necessary to first understand the overall health of the targeted population of older adults depending on lifestyle. The decline in both structural and functional characteristics with age requires broad, comprehensive diagnosis using a wide gamut of biological markers of health. This would demonstrate which components of health are the most susceptible to environmental influences, or lifestyle. It would therefore be possible to modify currently used health programs to better improve the quality of life of older people and prevent the onset of geriatric syndromes.

Therefore, the main objective of this study was to comparatively analyze the rate and magnitude of age-related changes between two groups of elderly women with different lifestyles living in Poland: the first a sample of women attending a University of the Third Age who had declared to lead an active lifestyle and another group of their less-active peers not involved in any seniors association.

Analysis was performed on both structural (somatic features, body composition, bone mineral density [BMD]) and functional (physical fitness, muscle strength, respiratory function, fine motor skills, body posture, and postural stability) biological markers of health.

\section{Materials and methods}

The study was performed under the financial assistance of the Ministry of Science and Higher Education (Project No N404 075337) and conducted in 2010-2012, excluding the months between November and March. The study design was approved by the Senate Ethics Committee for Scientific Research of the University School of Physical Education located in Wroclaw, Poland, on February 18, 2009. Invitations were sent to random senior citizens living in the province of Lower Silesia and its capital, Wroclaw, and seniors attending one of a number of Universities of the Third Age in the region. The inclusion criterion was good overall health and full functional autonomy. Participants were excluded if they presented any contraindications to performing a physical fitness test as determined by their doctor. All qualified individuals provided their written, voluntary consent to participate in the study.

In total, 417 women were recruited and divided into two groups. The first group, named "Senior Women" (S), included 330 women with a mean age of 65.4 years (standard deviation $[\mathrm{SD}]=4.2$ ) who were not involved in any seniors association and did not declare that they led an organized, active lifestyle. The second group was composed of 87 women attending one of several Universities of the Third Age in Lower Silesia. This group was named "University of the Third Age" (U3A) and had a mean age of 64.4 years $(S D=3.3)$. This was a group of active seniors who had been pursuing an active lifestyle for at least 3 years through the wide range of courses and activities offered by their respective University of the Third Age, promoting mental well-being, physical fitness, and social engagement.

All were informed about the purpose of the study, its protocol, and conditions for participation. Before testing, the participants completed a questionnaire collecting personal data and information on their current state of health. The results are presented in Table 1.

This information was first collected before the study period by conducting a series of interviews, during which information was provided about the purpose of the study, its 
Table I Personal questionnaire results of the group of seniors

\begin{tabular}{lll}
\hline Results of the questionnaire & S (\%) & U3A (\%) \\
\hline Marital status & & \\
Married & 50.0 & 48.3 \\
Single & 5.2 & 6.0 \\
Widowed & 26.8 & 25.3 \\
Divorced & 18.0 & 19.5 \\
Total & 100 & 100 \\
Education & & \\
Higher & 36.4 & 43.7 \\
Secondary & 51.5 & 52.9 \\
Primary & 12.1 & 3.4 \\
Total & 100 & 100 \\
Self-rated health & & \\
Very good & 3.0 & 2.3 \\
Good & 51.2 & 58.6 \\
Average & 40.9 & 36.8 \\
Poor & 3.4 & 2.3 \\
Very poor & 1.5 & 0.0 \\
Total & 100 & 100 \\
Falls in the preceding year & & \\
No & 75 & 80 \\
Yes & 25 & 20 \\
Total & 100 & 100 \\
\hline
\end{tabular}

Abbreviations: S, Senior Women; U3A, University of the Third Age.

protocol, and conditions for participation. After inclusion, the participants were measured during morning hours for various structural and functional biological markers of health. All measurements were performed by faculty members of the Department of Biokinetics Research of the University of Physical Education in Wroclaw, Poland, ISO 9001:2009 certified (Certificate No PW-48606-10E).

\section{Structural characteristics}

\section{Somatic characteristics}

Measurements of body height and mass and waist and hip circumference were taken to calculate the body mass index (BMI) and the waist-hip ratio (WHR) to assess body fat distribution.

\section{Body composition}

Body composition was measured using an MC-180 MA analyzer (Tanita Corporation, Tokyo, Japan) using the following variables: fat mass (FATkg) $(\mathrm{kg})$ and FAT\% (\% of body mass), lean body mass ( $\mathrm{kg})$, total body water $(\mathrm{kg})$, and muscle mass $(\mathrm{kg})$.

\section{Bone mineral density}

BMD was measured at the distal epiphysis of the radius of the nondominant forearm by peripheral dual-energy X-ray absorptiometry using an EXA-3000 densitometer (Osteosys Co. Ltd., Seoul, South Korea) with the following variables:
BMD $\left(\mathrm{g} / \mathrm{cm}^{2}\right), T$ score or ideal \%BMD (\%), and $Z$ score or age-matched $\% \mathrm{BMD}(\%)$.

\section{Functional characteristics \\ Physical fitness}

Participants' functional fitness was assessed using a test battery specifically designed for older adults, the Senior Fitness Test (also known as the Fullerton Functional Fitness Test). ${ }^{24}$ It is used to measure upper and lower body muscle strength (Chair Stand [n] and Arm Curl [n] tests), cardiovascular endurance (6-min Walk [m]), upper and lower body strength and flexibility (Chair Sit-and-Reach [cm] and Back Scratch $[\mathrm{cm}]$, respectively), and agility and dynamic balance (8-foot Up-and-Go [s]).

\section{Dominant handgrip strength}

Grip strength (kg) was measured by a 5030J1 hand dynamometer (Saehan, Masan, South Korea).

\section{Knee flexor and knee extensor muscle strength}

This was assessed by a multifunctional diagnostic physical therapy chair (model Ametyst II, Technomex, Poland) connected to a torque gauge transducer approved for medical use (Reg No PL/DR 011563). Peak torque values of the quadriceps muscle $\left(M_{\max } \mathrm{m}\right.$. quadriceps [N.m] ) and the knee flexor muscles $\left(M_{\max } \mathrm{mm}\right.$. knee flexors $\left.[\mathrm{N} \cdot \mathrm{m}]\right)$ were measured. Participants performed three isometric contractions with their dominant lower extremity. The best result out of three was selected for analysis.

\section{Respiratory function}

A FlowScreen spirometer (780.578; version 1.3, Jaeger, Würzburg, Germany) was used to measure respiratory function. All procedures were in accordance with the guidelines of the American Thoracic Society. ${ }^{25,26}$ Analysis was performed on the flow-volume loop of forced expiratory flow/volume of exhaled air by measuring the following variables: forced vital capacity (FVC $[\mathrm{L}]$ ), forced expiratory volume in $1 \mathrm{~s}$ $\left(\mathrm{FEV}_{1}[\mathrm{~L}]\right.$ ), the ratio of $\mathrm{FEV}_{1}$ to $\mathrm{FVC}$ (Tiffeneau index [\%]), and peak expiratory flow $(\mathrm{L} / \mathrm{s})$.

\section{Fine motor skills}

Hand performance was analyzed using the Motor Performance Series (MLS, S3 short form as adapted by Vassella) ${ }^{27}$ test battery part of the Vienna Test System. The MLS was developed by KJ Schoppe; ${ }^{28}$ it is based on Hamsterl's ${ }^{29}$ factor-analytic examination of fine motor skills. This test is performed on a work panel device with various contact 
surfaces where a stylus is used to perform static and dynamic tasks. For the purposes of this study, three motor skill tests were selected: Line Tracking to measure the precision of arm-hand movements (Line Tracking number of errors [n] and Line Tracking total time [s]), Inserting Pins to measure hand and finger dexterity (Inserting Pins total time [s]), and Tapping to measure wrist-finger speed (Tapping number of accurate hits $[\mathrm{n}])$.

\section{Postural stability}

An assessment of participants' static balance involved using an AccuSway Plus forceplate (AMTI, Watertown, MA, USA) and AMTI Balance Clinic software (version 2.01.00). Testing was performed with the eyes open and closed. Two centerof-pressure (COP) variables were measured: eyes-closed COP displacement $\left(\mathrm{mm}^{2}\right)$ and eyes-open COP displacement $\left(\mathrm{mm}^{2}\right)$. The results of three stabilographic measures were averaged for analysis.

\section{Body posture}

A postural assessment was performed using the Zebris APGMS Pointer analysis system (Technomex, Poland) to topographically measure the curvature of the spinal column in the static position by selected anatomical points on the back. Averaged measures of the thoracic kyphosis $\left(^{\circ}\right)$, lumbar lordosis $\left(^{\circ}\right)$, trunk tilt $\left(^{\circ}\right)$, and pelvic tilt $\left(^{\circ}\right.$ ) were taken.

\section{Statistical analyses}

Normality of the data was checked using the Shapiro-Wilk test, finding no statistical reason to reject the hypothesis of normal distribution. The results were statistically analyzed after calculating basic descriptive statistics for both groups, including arithmetic means $(\vec{x})$ and SDs. Comparison of the mean values between the two groups of active and lessactive women was performed using the Student's $t$-tests for independent samples. The correlations between the measured variables and age were determined using simple regression analysis by the equation $x=b_{0}+b_{\text {age }} \times$ age, and are presented in both graphical and table forms with significance tests for each of the equation coefficients. A value of $P \leq 0.05$ was considered statistically significant and marked in bold in the tables. Statistica 9.1 software (Statsoft, Kraków, Poland) was used for all analyses.

\section{Results}

Comparisons of the mean structural and functional characteristics between the two groups of women are presented in Tables 2 and 3, respectively, including Student's $t$ statistics and $P$-values.

No statistically significant differences were noted in the structural characteristics of the two groups (Table 2).

Statistically significant differences were noted in certain functional characteristics (Table 3). The active women (U3A) were characterized by statistically significantly higher levels of cardiovascular endurance, lower extremity muscle strength, $\mathrm{FEV}_{1}$, and hand precision and movement speed. However, this group (U3A) performed worse than the inactive women (S) in the Chair Stand test measuring agility and dynamic balance (Table 3 ). In addition, when compared to the inactive women (S), the active women (U3A) achieved statistically significantly better scores for body posture (Table 3 ).

The onset of age-related changes in both groups was characterized using simple linear regression for each of the structural and functional characteristics. An evaluation of the regression coefficients for the structural characteristics as a

Table 2 Differences in the structural characteristics between the groups of Seniors $(S)$ and University of the Third Age attendees (U3A)

\begin{tabular}{|c|c|c|c|c|c|c|}
\hline \multirow[t]{2}{*}{ Variable } & \multicolumn{2}{|l|}{$\mathbf{S}$} & \multicolumn{2}{|l|}{ U3A } & \multicolumn{2}{|c|}{ Student's $t$-test } \\
\hline & $\overline{\bar{x}}$ & SD & $\bar{x}$ & SD & $t$ & $P$ \\
\hline BMI $\left(\mathrm{kg} / \mathrm{m}^{2}\right)$ & 28.26 & 4.65 & 27.63 & 4.57 & 1.12 & 0.2629 \\
\hline WHR & 0.85 & 0.07 & 0.84 & 0.06 & 0.85 & 0.3968 \\
\hline FAT\% (\%) & 35.45 & 4.87 & 34.76 & 5.13 & 1.16 & 0.2454 \\
\hline FATkg (kg) & 25.35 & 7.21 & 24.89 & 7.34 & 0.53 & 0.5946 \\
\hline LBM (kg) & 44.95 & 5.07 & 45.38 & 5.62 & -0.69 & 0.4880 \\
\hline TBW (kg) & 31.71 & 3.64 & 32.03 & 4.03 & -0.72 & 0.4721 \\
\hline MM (kg) & 42.66 & 4.83 & 43.07 & 5.34 & -0.69 & 0.4886 \\
\hline $\operatorname{BMD}\left(\mathrm{g} / \mathrm{cm}^{2}\right)$ & 0.335 & 0.082 & 0.336 & $0.08 I$ & -0.06 & 0.9552 \\
\hline$T$ score $(\%)$ & 68.43 & 16.02 & 68.72 & 16.37 & -0.15 & 0.8800 \\
\hline Z score (\%) & 87.90 & 20.78 & 87.96 & 21.28 & -0.02 & 0.9820 \\
\hline
\end{tabular}

Abbreviations: SD, standard deviation; BMI, body mass index; WHR, waist-hip ratio; FAT\%, \% of body mass; FATkg, fat mass; LBM, lean body mass; TBW, total body water; MM, muscle mass; BMD, bone mineral density. 
Table 3 Differences in the functional characteristics between the groups of Seniors (S) and University of the Third Age attendees (U3A)

\begin{tabular}{|c|c|c|c|c|c|c|}
\hline \multirow[t]{2}{*}{ Variable } & \multicolumn{2}{|l|}{$\mathbf{S}$} & \multicolumn{2}{|l|}{ U3A } & \multicolumn{2}{|c|}{ Student's $t$-test } \\
\hline & $\overline{\bar{x}}$ & SD & $\bar{x}$ & SD & $t$ & $P$ \\
\hline Chair Stand (n) & 16.66 & 3.83 & 17.24 & 4.17 & -1.23 & 0.2199 \\
\hline Arm Curl (n) & 19.99 & 4.57 & 20.53 & 4.10 & -1.00 & 0.3195 \\
\hline 6-min Walk (m) & 554.07 & 81.60 & 580.64 & 88.16 & -2.66 & 0.0082 \\
\hline Chair Sit-and-Reach (cm) & 5.28 & 9.02 & 7.14 & 7.67 & -1.76 & 0.0796 \\
\hline Back Scratch (cm) & -2.00 & 7.50 & -0.42 & 7.17 & -1.77 & 0.0782 \\
\hline 8-foot Up-and-Go (s) & 5.68 & 0.91 & 6.15 & 1.29 & -3.90 & 0.0001 \\
\hline Dominant handgrip strength (kg) & 25.40 & 6.15 & 26.13 & 8.28 & -0.91 & $0.365 I$ \\
\hline$M_{\max } \mathrm{m}$. quadriceps $(\mathrm{N} \cdot \mathrm{m})$ & 180.05 & 72.26 & 231.70 & 84.84 & $-5.7 \mathrm{I}$ & 0.0000 \\
\hline$M_{\max } \mathrm{mm}$. knee flexors $(\mathrm{N} \cdot \mathrm{m})$ & 89.40 & 37.43 & 111.19 & 39.51 & -4.77 & 0.0000 \\
\hline $\mathrm{FVC}(\mathrm{L})$ & 2.76 & 0.47 & 2.92 & 0.48 & -2.73 & 0.0066 \\
\hline $\mathrm{FEV}_{1}(\mathrm{~L})$ & 2.19 & 0.42 & 2.29 & 0.43 & -1.88 & 0.0605 \\
\hline Tiffeneau index (\%) & 79.44 & 7.04 & 78.48 & 6.87 & 1.15 & 0.2526 \\
\hline $\operatorname{PEF}(\mathrm{L} / \mathrm{s})$ & 4.43 & 1.24 & 4.42 & 1.15 & 0.08 & 0.9354 \\
\hline Line Tracking number of errors $(n)$ & 26.44 & 9.71 & 23.61 & 8.37 & 2.49 & 0.0133 \\
\hline Line Tracking total time (s) & 25.10 & 10.91 & 23.43 & $|2.3|$ & 1.23 & 0.2176 \\
\hline Inserting Pins total time (s) & 45.15 & 6.19 & 43.47 & 4.32 & 2.38 & 0.0177 \\
\hline Tapping accurate hits (n) & 178.58 & 21.04 & 186.82 & 18.08 & -3.34 & 0.0009 \\
\hline Eyes-open COP displacement $\left(\mathrm{mm}^{2}\right)$ & 2.82 & 1.36 & 2.91 & 2.14 & -0.46 & 0.6481 \\
\hline Eyes-closed COP displacement $\left(\mathrm{mm}^{2}\right)$ & 4.86 & 3.21 & 4.76 & 3.23 & 0.26 & 0.7987 \\
\hline Total thoracic kyphosis $\left({ }^{\circ}\right)$ & 46.11 & 15.87 & 42.43 & 14.32 & 1.96 & 0.0502 \\
\hline Total lumbar lordosis $\left({ }^{\circ}\right)$ & 29.22 & 11.75 & 23.40 & 12.78 & 4.03 & $0.000 \mathrm{I}$ \\
\hline Trunk tilt $\left(^{\circ}\right)$ & 4.68 & 2.99 & 4.35 & 3.32 & 0.90 & 0.3705 \\
\hline Pelvic tilt $\left({ }^{\circ}\right)$ & 22.33 & 10.98 & 18.79 & 11.33 & 2.65 & 0.0082 \\
\hline
\end{tabular}

Note: Statistically significant differences of $P \leq 0.05$ are marked in bold.

Abbreviations: SD, standard deviation; FVC, forced vital capacity; FEV ${ }_{1}$, forced expiratory volume in I s; PEF, peak expiratory flow; COP, center-of-pressure.

function of age is presented in Table 4 and for the functional characteristics in Table 5.

In both groups of women, the characteristics describing mass-height ratio (BMI) and body fat distribution (WHR) and its amount (FATkg) did not show significant changes with age. In the group of inactive seniors (S), a significant decrease in lean body mass and muscle mass was found, resulting in a slight change in body composition with an increase in the percentage of fat (Table 4). The most significant age-related changes were noted in BMD, with a significant decrease in BMD measures in both groups. The magnitude of these changes was similar for the active (U3A) and inactive (S) women (Figure 1).

Regression analysis on the functional characteristics of the participants found a statistically significant decline in a number of results with age, with more of these changes observed in the group of inactive seniors (S) (Table 5). Above all, this applied to the physical fitness measures assessed by the Senior Fitness Test and the results of hand and lower extremity (extensors and flexors) muscle strength. A decrease was also observed in the respiratory efficiency and fine motor skill performance. Statistically significant changes as a function of age in the group of active (U3A) women were noted in cardiovascular endurance (6-min Walk) and the analyzed respiratory variables (Table 5). Measures of static balance and body posture as a function of age were found to plateau in the women over the studied age range. Among the functional characteristics, the fastest rate of age-related change concerned agility and dynamic balance as assessed by the 8-foot Up-and-Go test and forced vital capacity but only among the group of inactive seniors (S) (Figures 2 and 3).

Further analysis of the results found that the greatest difference between the active and inactive women was in the rate of change of muscle strength with age. These changes are most readily visible when the linear regression line is plotted for knee extensor (Figure 4) and flexor (Figure 5) muscle strength.

\section{Discussion}

Although older individuals frequently require regular or even constant care, the extensive knowledge and experience as well as the time and energy they possess enable them to significantly contribute to society. An active approach to aging may not only improve their quality of life but also offer a number of benefits to local communities. Today's approach to the issue of old age has recognized the need to socially 
Table 4 Regression coefficients of the structural characteristics as a function of age

\begin{tabular}{|c|c|c|c|c|c|c|c|c|c|}
\hline \multirow{2}{*}{$\begin{array}{l}\text { Dependent } \\
\text { variable }\end{array}$} & \multirow[t]{2}{*}{ Group } & \multicolumn{4}{|l|}{ Intercept value } & \multicolumn{4}{|c|}{ Coefficient for the age } \\
\hline & & Coefficient $b_{0}$ & Standard error $b_{0}$ & $t$ & $P$ & Coefficient $b_{\text {age }}$ & Standard error $b_{\text {age }}$ & $t$ & $\mathbf{P}$ \\
\hline \multirow[t]{2}{*}{ BMI } & $S$ & 25.631 & 4.001 & 6.41 & 0.0000 & 0.040 & 0.061 & 0.66 & 0.5108 \\
\hline & U3A & 25.024 & 9.847 & 2.54 & 0.0129 & 0.041 & 0.153 & 0.27 & 0.7914 \\
\hline \multirow[t]{2}{*}{ WHR } & $\mathrm{S}$ & 0.925 & 0.062 & 14.99 & 0.0000 & -0.001 & 0.001 & -1.19 & 0.2361 \\
\hline & U3A & 0.633 & 0.131 & 4.83 & 0.0000 & 0.003 & 0.002 & 1.61 & 0.1102 \\
\hline \multirow[t]{2}{*}{ FAT\% } & $S$ & 31.623 & 4.191 & 7.55 & 0.0000 & 0.059 & 0.064 & 0.92 & 0.3605 \\
\hline & U3A & 24.036 & 10.988 & 2.19 & 0.0314 & 0.167 & 0.170 & 0.98 & 0.3311 \\
\hline \multirow[t]{2}{*}{ FATkg } & S & 26.725 & 6.211 & 4.30 & 0.0000 & -0.021 & 0.095 & -0.22 & 0.8248 \\
\hline & U3A & 23.721 & 15.818 & 1.50 & 0.1374 & 0.018 & 0.245 & 0.07 & 0.9413 \\
\hline \multirow[t]{2}{*}{ LBM } & S & 56.064 & 4.329 & 12.95 & 0.0000 & -0.170 & 0.066 & -2.57 & 0.0105 \\
\hline & U3A & 59.387 & 12.004 & 4.95 & 0.0000 & -0.217 & 0.186 & -1.17 & 0.2460 \\
\hline \multirow[t]{2}{*}{ TBW } & $S$ & 40.720 & 3.095 & 13.16 & 0.0000 & -0.138 & 0.047 & -2.92 & 0.0038 \\
\hline & U3A & 43.175 & 8.586 & 5.03 & 0.0000 & -0.173 & 0.133 & -1.30 & 0.1973 \\
\hline \multirow[t]{2}{*}{ MM } & $S$ & 53.264 & 4.117 & 12.94 & 0.0000 & -0.162 & 0.063 & -2.58 & 0.0103 \\
\hline & U3A & 56.371 & 11.414 & 4.94 & 0.0000 & -0.206 & 0.177 & -1.17 & 0.2468 \\
\hline \multirow[t]{2}{*}{ BMD } & $S$ & 0.679 & 0.068 & 9.93 & 0.0000 & -0.005 & 0.001 & -5.04 & 0.0000 \\
\hline & U3A & 0.765 & 0.169 & 4.53 & 0.0000 & -0.007 & 0.003 & -2.55 & 0.0127 \\
\hline \multirow[t]{2}{*}{$T$ score } & $S$ & 132.950 & 13.340 & 9.97 & 0.0000 & -0.986 & 0.204 & -4.85 & 0.0000 \\
\hline & U3A & 155.319 & 33.979 & 4.57 & 0.0000 & -1.345 & 0.527 & -2.55 & 0.0125 \\
\hline \multirow[t]{2}{*}{$Z$ score } & $\mathrm{S}$ & 158.268 & 17.476 & 9.06 & 0.0000 & -1.076 & 0.267 & -4.03 & 0.0001 \\
\hline & U3A & 178.742 & 44.764 & 3.99 & 0.0001 & -1.410 & 0.694 & -2.03 & 0.0454 \\
\hline
\end{tabular}

Note: Statistically significant differences of $P \leq 0.05$ are marked in bold.

Abbreviations: BMI, body mass index; WHR, waist-hip ratio; FAT\%, \% of body mass; FATkg, fat mass; LBM, lean body mass; TBW, total body water; MM, muscle mass; BMD, bone mineral density; S, Senior Women; U3A, University of the Third Age.

activate the elderly by providing them with opportunities to expand their social circle and meet their needs for selfdevelopment, education, and physical activity.

It is estimated that by 2050 the number of elderly individuals in Poland will be $35 \%$ of the population. ${ }^{30}$ The changing age structure in Poland as well as other countries is necessitating the creation of opportunities for this population segment to age positively. Factors that need to be taken into consideration include maintaining functional efficiency, independence, self-reliance, and the ability to perform basic activities of daily living. ${ }^{31}$

The goal of our study was to research differences among various biological markers of health depending on lifestyle in a group of elderly women. The more active participants were attending a University of the Third Age and declared to lead a very active life, whereas their less-active peers were not involved in any organized forms of physical activity or seniors association.

A review of the literature on the physical activity levels of the elderly finds that middle-aged and older adults are less active than younger-aged groups. ${ }^{32}$ According to Krems et al, ${ }^{33}$ older people are more reluctant to engage in physical activity, with previous studies reporting that the proportion of physically active individuals markedly decreases from the age range of 60-64 years (78\%) to 65-69 years $(22 \%)$. These findings are consistent with those of Ruuskanen and

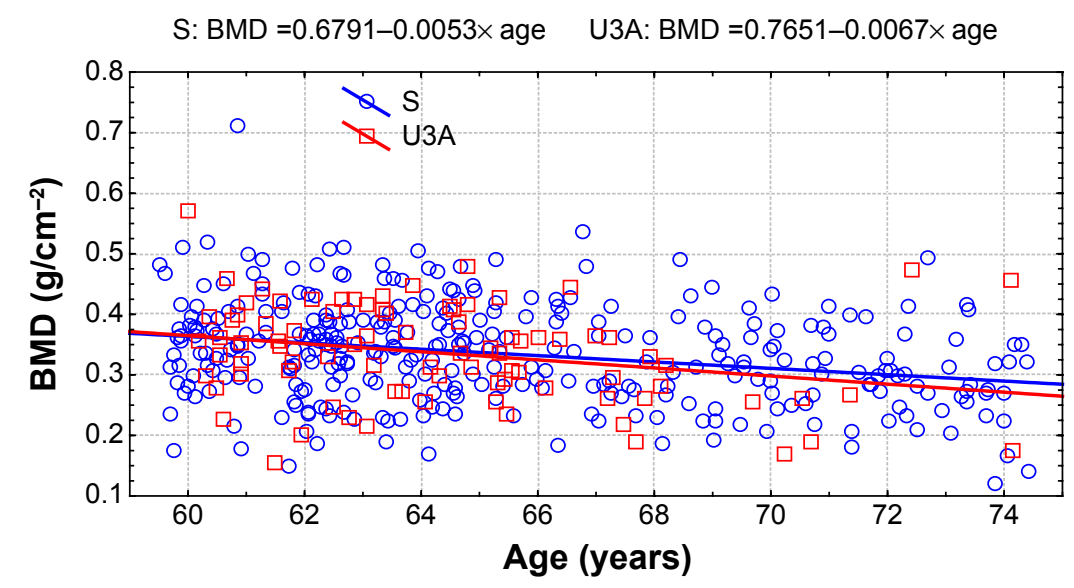

Figure I Changes with age in bone mineral density (BMD) in the groups of active (U3A) and inactive (S) women. Abbreviations: S, Senior Women; U3A, University of the Third Age. 
Table 5 Regression coefficients of the functional characteristics as a function of age

\begin{tabular}{|c|c|c|c|c|c|c|c|c|c|}
\hline \multirow[t]{2}{*}{ Dependent variable } & \multirow[t]{2}{*}{ Group } & \multicolumn{4}{|c|}{ Intercept value } & \multicolumn{4}{|c|}{ Coefficient for the age } \\
\hline & & $\begin{array}{l}\text { Coefficient } \\
b_{0}\end{array}$ & $\begin{array}{l}\text { Standard } \\
\text { error } b_{0}\end{array}$ & $t$ & $P$ & $\begin{array}{l}\text { Coefficient } \\
b_{\text {age }}\end{array}$ & $\begin{array}{l}\text { Standard } \\
\text { error } b_{\text {age }}\end{array}$ & $t$ & $P$ \\
\hline \multirow[t]{2}{*}{ Chair Stand } & $S$ & 25.388 & 3.263 & 7.78 & 0.0000 & -0.133 & 0.050 & -2.68 & 0.0078 \\
\hline & U3A & 14.897 & 8.986 & 1.66 & 0.1010 & 0.036 & 0.139 & 0.26 & 0.7945 \\
\hline \multirow[t]{2}{*}{ Arm Curl } & S & 29.597 & 3.904 & 7.58 & 0.0000 & -0.147 & 0.060 & -2.47 & 0.0142 \\
\hline & U3A & 21.546 & 8.830 & 2.44 & 0.0168 & -0.016 & 0.137 & -0.12 & 0.9084 \\
\hline \multirow[t]{2}{*}{ 6-min Walk } & $\mathrm{S}$ & 882.032 & 67.942 & 12.98 & 0.0000 & -5.014 & 1.037 & -4.84 & 0.0000 \\
\hline & U3A & I,009.967 & 184.068 & 5.49 & 0.0000 & -6.667 & 2.855 & -2.34 & 0.0219 \\
\hline \multirow[t]{2}{*}{ Chair Sit-and-Reach } & $\mathrm{S}$ & 16.621 & 7.746 & 2.15 & 0.0326 & -0.173 & 0.118 & -1.47 & 0.1435 \\
\hline & U3A & 21.454 & 16.445 & 1.30 & 0.1956 & -0.222 & 0.255 & -0.87 & 0.3859 \\
\hline \multirow[t]{2}{*}{ Back Scratch } & $\mathrm{s}$ & 17.206 & 6.372 & 2.70 & 0.0073 & -0.294 & 0.097 & -3.02 & 0.0027 \\
\hline & U3A & 20.418 & 15.277 & 1.34 & 0.1849 & -0.324 & 0.237 & -1.37 & 0.1756 \\
\hline \multirow[t]{2}{*}{ 8-foot Up-and-Go } & S & 0.600 & 0.732 & 0.82 & 0.4128 & 0.078 & 0.011 & 6.96 & 0.0000 \\
\hline & U3A & 1.687 & 2.738 & 0.62 & 0.5394 & 0.069 & 0.042 & 1.63 & 0.1062 \\
\hline \multirow[t]{2}{*}{ Dominant handgrip strength } & $\mathrm{S}$ & 38.196 & 5.252 & 7.27 & 0.0000 & -0.196 & 0.080 & -2.44 & 0.0152 \\
\hline & U3A & 12.625 & 17.783 & 0.71 & 0.4797 & 0.210 & 0.276 & 0.76 & 0.4493 \\
\hline \multirow[t]{2}{*}{$M_{\max } m$. quadriceps } & $\mathrm{S}$ & 418.426 & 60.864 & 6.87 & 0.0000 & -3.644 & 0.929 & -3.92 & 0.0001 \\
\hline & U3A & 177.865 & 182.639 & 0.97 & 0.3329 & 0.836 & 2.833 & 0.30 & 0.7686 \\
\hline \multirow{2}{*}{$M_{\max } \mathrm{mm}$. knee flexors } & $\mathrm{S}$ & 206.090 & 31.607 & 6.52 & 0.0000 & -1.784 & 0.482 & -3.70 & 0.0003 \\
\hline & U3A & 103.165 & 85.087 & 1.21 & 0.2287 & 0.125 & 1.320 & 0.09 & 0.9250 \\
\hline \multirow[t]{2}{*}{ FVC } & $S$ & 5.328 & 0.384 & 13.89 & 0.0000 & -0.039 & 0.006 & $-6.7 \mid$ & 0.0000 \\
\hline & U3A & 5.839 & 0.982 & 5.95 & 0.0000 & -0.045 & 0.015 & -2.98 & 0.0038 \\
\hline \multirow[t]{2}{*}{$\mathrm{FEV}_{1}$} & $\mathrm{~S}$ & 4.255 & $0.34 I$ & 12.48 & 0.0000 & -0.032 & 0.005 & -6.06 & 0.0000 \\
\hline & U3A & 4.304 & 0.890 & 4.84 & 0.0000 & -0.031 & 0.014 & -2.27 & 0.0259 \\
\hline \multirow[t]{2}{*}{ Tiffeneau index } & $S$ & 80.430 & 6.063 & 13.27 & 0.0000 & -0.015 & 0.092 & -0.16 & 0.8706 \\
\hline & U3A & 66.551 & 14.733 & 4.52 & 0.0000 & 0.185 & 0.229 & 0.81 & 0.4199 \\
\hline \multirow[t]{2}{*}{ PEF } & $S$ & 8.542 & 1.045 & 8.17 & 0.0000 & -0.063 & 0.016 & -3.94 & $0.000 \mathrm{I}$ \\
\hline & U3A & 7.131 & 2.459 & 2.90 & 0.0048 & -0.042 & 0.038 & -1.10 & 0.2732 \\
\hline \multirow[t]{2}{*}{ Line Tracking number of errors } & $\mathrm{S}$ & 9.776 & 8.319 & 1.18 & 0.2408 & 0.255 & 0.127 & 2.01 & 0.0455 \\
\hline & U3A & 46.287 & 17.859 & 2.59 & 0.0112 & -0.352 & 0.277 & -1.27 & 0.2070 \\
\hline \multirow[t]{2}{*}{ Line Tracking total time } & S & 6.589 & 9.348 & 0.70 & 0.4814 & 0.283 & 0.143 & 1.98 & $0.048 I$ \\
\hline & U3A & 11.237 & 26.490 & 0.42 & 0.6725 & 0.189 & 0.411 & 0.46 & 0.6460 \\
\hline \multirow[t]{2}{*}{ Inserting Pins total time } & $\mathrm{S}$ & 16.774 & 5.097 & 3.29 & 0.0011 & 0.434 & 0.078 & 5.58 & 0.0000 \\
\hline & U3A & 20.225 & 8.947 & 2.26 & 0.0263 & 0.361 & 0.139 & 2.60 & 0.0109 \\
\hline Tapping accurate hits & $S$ & 247.521 & 17.729 & 13.96 & 0.0000 & -1.054 & 0.270 & -3.90 & $0.000 \mathrm{I}$ \\
\hline & U3A & $193.78 \mid$ & 38.937 & 4.98 & 0.0000 & -0.108 & 0.604 & -0.18 & 0.8583 \\
\hline Eyes-open COP displacement & $\mathrm{S}$ & 0.574 & 1.163 & 0.49 & 0.6221 & 0.034 & 0.018 & 1.94 & 0.0534 \\
\hline & U3A & $-5 .|3|$ & 4.518 & -1.14 & 0.2592 & 0.125 & 0.070 & 1.78 & 0.0784 \\
\hline Eyes-closed COP displacement & $\mathrm{S}$ & 3.973 & 2.767 & $\mathrm{I} .44$ & 0.1520 & 0.014 & 0.042 & 0.32 & $0.748 I$ \\
\hline & U3A & -3.594 & 6.889 & -0.52 & 0.6033 & 0.130 & 0.107 & 1.21 & 0.2280 \\
\hline Total thoracic kyphosis & $\mathrm{S}$ & 38.107 & 13.669 & 2.79 & 0.0056 & 0.122 & 0.209 & 0.59 & 0.5577 \\
\hline & U3A & 41.249 & 30.836 & 1.34 & 0.1846 & 0.018 & 0.478 & 0.04 & 0.9695 \\
\hline Total lumbar lordosis & $\mathrm{S}$ & 47.858 & 10.073 & 4.75 & 0.0000 & -0.285 & 0.154 & -1.85 & 0.0647 \\
\hline & U3A & 49.560 & 27.374 & 1.81 & 0.0738 & -0.406 & 0.425 & -0.96 & $0.34 \mid 4$ \\
\hline Trunk tilt & $S$ & 0.091 & 2.562 & 0.04 & 0.9717 & 0.070 & 0.039 & 1.79 & 0.0737 \\
\hline & U3A & 6.566 & $7.14 \mid$ & 0.92 & 0.3604 & -0.034 & 0.111 & -0.31 & 0.7564 \\
\hline Pelvic tilt & $S$ & 33.207 & 9.439 & 3.52 & 0.0005 & -0.166 & 0.144 & -1.15 & 0.2490 \\
\hline & U3A & 40.842 & 24.288 & 1.68 & 0.0963 & -0.342 & 0.377 & -0.91 & 0.3659 \\
\hline
\end{tabular}

Note: Statistically significant differences of $P \leq 0.05$ are marked in bold.

Abbreviations: FVC, forced vital capacity; FEV , forced expiratory volume in I s; PEF, peak expiratory flow; COP, center-of-pressure; S, Senior Women; U3A, University of the Third Age.

Ruoppila (1995), ${ }^{34}$ who showed that the percentage of women and men between 65 and 69 years of age taking up extra physical activity beyond that involved in day-to-day life fell from $27 \%$ to $20 \%$. The amount of physical activity was found to continually decrease with age, falling to a value of $5 \%$ for women aged 80-84 years. These findings reveal that the promotion of an active lifestyle is critical, as several studies ${ }^{35-37}$ have determined that a sedentary lifestyle, defined as a large amount of time spent sitting or lying down, proved to be a major risk factor for chronic diseases and disability. 


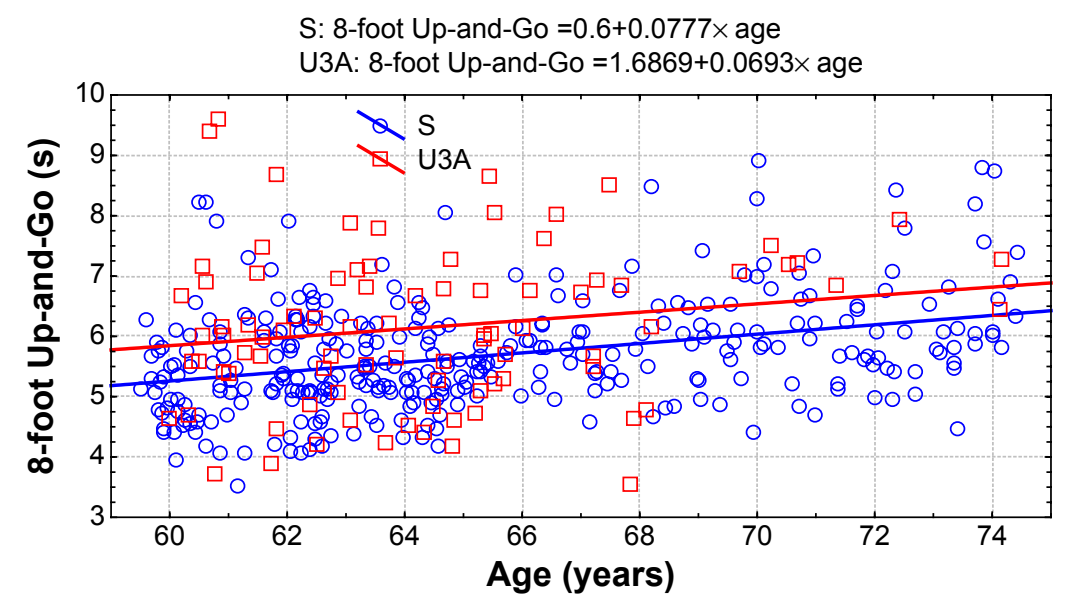

Figure 2 Changes with age in 8-foot Up-and-Go test in the groups of active (U3A) and inactive (S) women. Abbreviations: S, Senior Women; U3A, University of the Third Age.

Increased physical activity has been found to have a protective effect against functional limitations associated with aging ${ }^{38,39}$ by promoting beneficial changes in the body and thereby helping preserve the body's functional capabilities. This can help maintain or even improve the more basic components of physical fitness and efficiency. In a systematic review of the literature by Spirduso and Cronin, ${ }^{40}$ the administration of a long-term physical fitness program was found to increase the independence of the elderly in performing activities of daily living. Physical activity has also been found to significantly reduce the risk of many geriatric syndromes, playing an important role in the primary and secondary prevention of cardiovascular diseases, osteoporosis, some forms of cancer, and type 2 diabetes. ${ }^{41}$ The link between an active lifestyle and its ability to modify numerous life factors makes this an incredibly important element in improving health. ${ }^{42}$
Comparisons of the structural and functional characteristics of two groups of active and inactive women found that the groups were similar in terms of structural characteristics. However, statistically significant differences were found in a number of the functional characteristics. The active women (U3A) were characterized by better results in most of the functional measures, achieving statistically significantly higher scores for cardiovascular endurance, lower extremity muscle strength, $\mathrm{FEV}_{1}$, hand precision and movement speed, and body posture. The results of the questionnaires showed few differences between the groups except for the greater number of individuals with higher education in the U3A group. This may indicate that a health-promoting, active lifestyle is dependent on the level of education. No between-group differences were observed for marital status or self-rated health. The number of falls declared by the respondents was slightly higher for

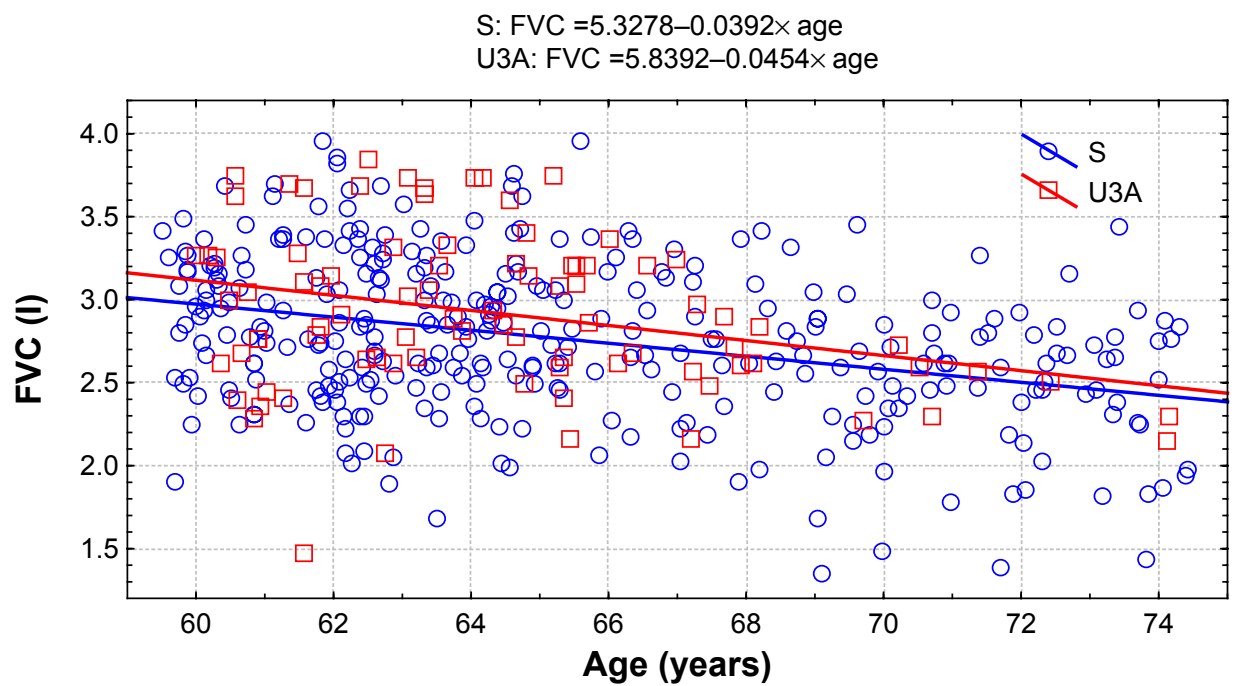

Figure 3 Changes with age in forced vital capacity (FVC) in the groups of active (U3A) and inactive (S) women. Abbreviations: S, Senior Women; U3A, University of the Third Age. 


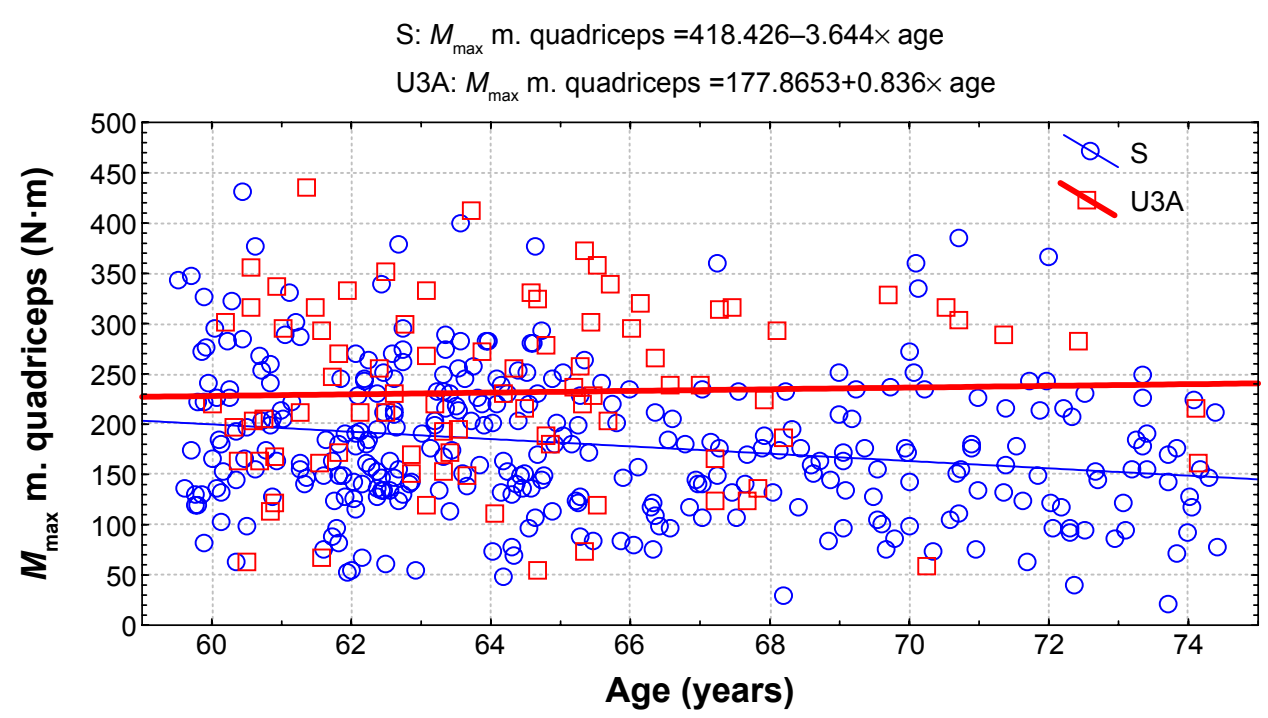

Figure 4 Changes with age in knee extensor muscle strength in the groups of active (U3A) and inactive (S) women. Abbreviations: S, Senior Women; U3A, University of the Third Age.

the less-active group S and may be linked, in part, to this group's poorer functional performance. This may nonetheless be the result of other factors influencing the elderly's lifestyle and quality of life.

Analysis was also performed on the rate of change and magnitude of the measured structural and functional biological markers of health. Simple linear regression of the structural characteristics showed that most of the changes associated with age concerned lean body mass and muscle mass. These changes were statistically significant in the group of inactive seniors $(\mathrm{S})$ and greater than in the active women attending a U3A. However, the most significant age-related changes in both the active and the inactive groups were noted in BMD, leading to a significant decrease in the measures of BMD in both the groups.

These observations confirm the findings of other researchers on the aging process. These include work on muscle physiology, finding increased sarcopenia with age. ${ }^{43}$ Many studies have also highlighted the importance of decreased BMD with age as another critical factor in the aging process, such as a strong correlation between low BMD and low-energy forearm fractures. ${ }^{44}$ Other research has determined low bone density as an important risk factor of osteoporotic hip fractures, with risk increasing in successive age groups. ${ }^{45}$

The results of the current study found no significant differences in mean bone density between the active and

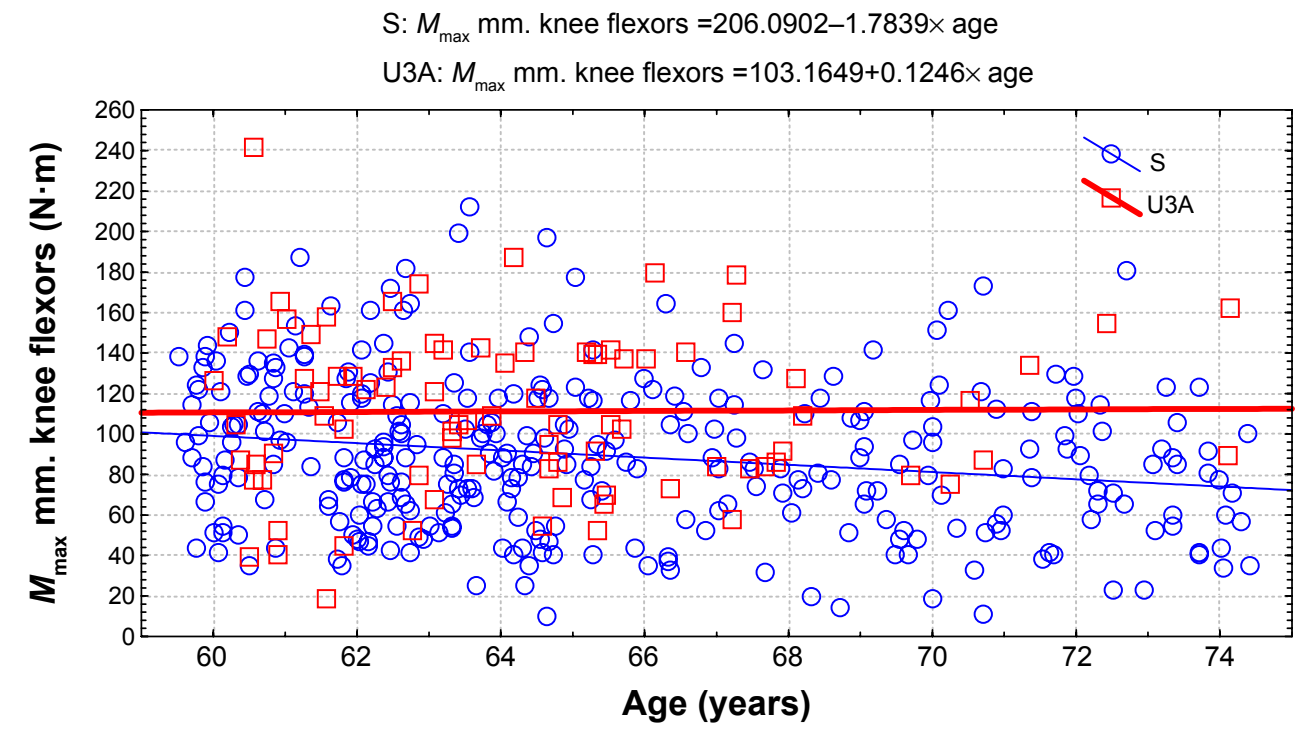

Figure 5 Changes with age in knee flexor muscle strength in the groups of active (U3A) and inactive (S) women. Abbreviations: S, Senior Women; U3A, University of the Third Age. 
less-active women as well as little difference in the rate of decrease of BMD with age. Bearing in mind that physical activity is recommended to counteract or reduce bone loss in the elderly, the results may indicate that the amount of physical activity performed by the U3A attendees may be too small to induce a positive health effect. In this context, it is worth mentioning that the mechanisms of mechanical loading on the aging skeleton are still not fully understood. ${ }^{46}$

Regression analysis on the functional characteristics of the participants found a statistically significant decline in a number of results with age. Above all, this applied to the participants' physical fitness levels, assessed by both the Senior Fitness Test and the strength measures of the hand and lower extremities. A decrease was also observed in the respiratory efficiency and fine motor skill performance. More statistically significant changes were observed in the group of inactive women.

Our results are consistent with those reported by other studies on the decreases in muscle strength and endurance and the rise in obesity in the elderly, all of which increase the risk of disability. ${ }^{47} \mathrm{~A}$ strong relationship was demonstrated between high BMI and low muscle strength with functional incapacity in older women. ${ }^{48}$

Regarding these results, the applicability of administering functional tests to older adults should be considered. The main purpose of physical activity in this population is to maintain sufficient levels of strength, endurance, flexibility, and mobility in order to remain independent. ${ }^{49}$ Maintaining an optimal level of muscular strength, both in the lower and upper parts of the body, is critical in preserving physical function in the elderly. ${ }^{50}$ The lower extremities stand out in particular, as they are necessary in such actions as climbing stairs, walking, or getting up from a chair or bathtub. Additionally, insufficient lower extremity strength has been associated with increased risk of falls, hip fracture, and disability. ${ }^{51}$ Rikli and Jones ${ }^{52}$ determined that the decline in lower extremity strength is approximately $15 \%$ per decade and that in the upper extremities is $12 \%$; Onder et al $(2002)^{53}$ reported similar changes. Besides strength, agility and dynamic balance have also been credited as very important factors in executing various mobility tasks. ${ }^{50}$ Although a significant decrease in flexibility is noted in the elderly, when compared with other characteristics, the differences with age are less pronounced. ${ }^{54}$ The impact of age also negatively affects aerobic fitness, with decreases noted from $5 \%$ to $15 \%,{ }^{55}$ and fine motor skill performance, leading to various hand disorders. The latter may be caused by a deterioration in skeletal muscle function (sarcopenia) ${ }^{56}$ or changes in the central $^{57}$ or peripheral ${ }^{58}$ nervous system.
The various activities proposed by $\mathrm{U} 3 \mathrm{~A}$ can help reduce the negative effects of aging. When combined with preventive gerontological measures, the incidence of disability and dependence on outside forms of care may markedly decrease. It was observed that elderly individuals attending a U3A were an intellectually and physically active group as confirmed in studies on their physical activity and ways of spending leisure time. ${ }^{19,59,60}$ The positive effects of various intervention programs for the elderly have been described in numerous studies, for example, on such physical fitness characteristics as walking, balance, endurance, and flexibility. ${ }^{61}$ However, in the literature, there are few reports that have analyzed the effects of aging on fine motor skills of the hands and an active lifestyle. Some of the available studies include one by Kalisch et $\mathrm{al}^{62}$ who described the limitations of performing everyday activities due to a deterioration of motor skills with age combined with a sedentary lifestyle. This study cited the works of Dik et $\mathrm{al}^{63}$ and Weuve et $\mathrm{al}^{64}$ who documented a relationship between physical activity and the fine motor skills of the hands in an elderly sample.

The incidence of falls has been found to increase with age. One in three people over the age of 65 years and one in two over the age of 80 experience at least one fall per year. ${ }^{54}$ Although most of the attention is focused on fractures in relation to bone mass and strength, numerous age-related changes have been found to be significantly related to fall risk. ${ }^{65}$ These include physiological, biological, anatomical age-related changes, the effects of medication, concomitant diseases, and environmental factors. Several studies have also demonstrated that weakness of the lower extremity muscles and impaired balance are important factors contributing to fall risk. ${ }^{66}$

Analysis of our study's results showed that the largest difference in age-related changes between the active and inactive women was in the recorded muscle strength values, whereas the results of static balance and body posture were found to plateau, with relatively stable results over the studied age ranges. However, the prevention of falls is extremely important as they are a major source of injuries and death in the elderly. A number of fall prevention programs have already been developed, with researchers having proved their effectiveness. ${ }^{67}$

The most recent scientific research on the relationship between environment and an active lifestyle stresses the role of demographic, biological, psychological, emotional, social, and cultural factors. ${ }^{68}$ Many studies have indicated the need to develop programs that promote a healthy, active lifestyle so as to delay and slow the effects of aging on physical and 
mental health. ${ }^{69}$ As rising health care costs are largely due to the aging of the population, a program based on an active approach to aging should be crucial in maintaining the health of the elderly. The results of the study confirm that the active approach to life of older adults, in this case attending a broadbased University of the Third Age, significantly contributes to more favorable results among the analyzed biological markers of health than among their less-active peers.

\section{Conclusion}

1. The best results among the tests assessing functional biological markers of health were found in the group of elderly women attending a University of the Third Age. This may stem from a larger variety of physical activity programs offered at this type of institution, and also from the higher education and active lifestyle of the surveyed women.

2. The study confirmed the effect of aging on numerous structural and functional characteristics in both active and less-active elderly women. The rate of change was larger in the group of seniors leading a less-active lifestyle, indicating the important role of a preventive gerontological approach and the participation of seniors in programs that accentuate the need for physical activity.

3. The accrued data on the sample populations' biological markers of health suggest that the active lifestyle characteristic of older women attending a University of the Third Age is associated with their greater levels of physical fitness and independence. This may be associated with the slightly smaller number of falls reported by this group.

\section{Acknowledgment}

This study was funded by the Ministry of Science and Higher Education in Poland (Project No N404 075337).

\section{Author information}

The authors are experts in the fields of physiotherapy, antropokinetics, and gerokinesiology. They have authored numerous publications on issues of aging, falls risk factors, and determinants of physical activity of older people.

\section{Disclosure}

The authors report no conflicts of interest in this work.

\section{References}

1. Lampinen P, Heikkinen RL, Kauppinen M, Heikkinen E. Activity as a predictor of mental well-being among older adults. Aging Ment Health. 2006;10:454-466.
2. Cherkas LF, Hunkin JL, Kato BS. The association between physical activity in leisure time and leukocyte telomere length. Arch Intern Med. 2008;168:154-158.

3. Chipperfield JG. Everyday physical activity as a predictor of latelife mortality. Gerontologist. 2008;48:349-357.

4. Emery CF, Blumenthal JA. Perceived change among participants in an exercise program for older adults. Gerontologist. 1990;30: 516-521.

5. Arai A, Ishida K, Tomimori M, Katsumata Y, Grove JS, Tamashiro H. Association between lifestyle activity and depressed mood among home-dwelling older people: a community-based study in Japan. Aging Ment Health. 2007;11:547-555.

6. Paul C, Ayis S, Ebrahim S. Psychological distress, loneliness and disability in old age. Psychol Health Med. 2006;11:221-232.

7. Miller E, Buys L, Roberto K. Feeling blue? The importance of a confidant for the well-being of older rural married Australian and American men. Ageing Int. 2006;31:283-295.

8. Adams KB, Sanders S, Auth EA. Loneliness and depression in independent living retirement communities: risk and resilience factors. Ageing Ment Health. 2004;8:475-485.

9. Coe RM, Morley JE, Tumosa N. Social and community aspect of aging. Ageing Successfully. 2005;15:3-20.

10. Antonucci TC, Lansford JE, Akiyama H. Impact of positive and negative aspects of marital relationships and friendships on well-being of older adults. Appl Develop Sci. 2001;5:68-75.

11. Martina CM, Stevens NL. Breaking the cycle of loneliness? Psychological effect of a friendship enrichment program for older women. Aging Ment Health. 2006;10:467-475.

12. WHO. Active Ageing: A Policy Framework. Geneva, Switzerland: World Health Organization; 2002. Available from: http://whqlibdoc. who.int/hq/2002/who_nmh_nph_02.8.pdf. Accessed March 25, 2009.

13. Davey J. Active ageing and education in mid and later life. Aging Soc. 2002;22:95-113.

14. Yenerall JD. Educating an aging society: the university of the third age in Finland. Educ Gerontol. 2003;29:703-716.

15. Principi A, Lemura G. Education for older people in Italy. Educ Gerontol. 2009;35:246-259.

16. Swindell R. U3A (the University of the Third Age) in Australia: a model for successful ageing. Ageing Soc. 1993;13:245-266.

17. Huang CS. The development of a university for older adults in Taiwan: an interpretive perspective. Educ Gerontol. 2005;31:503-519.

18. Hori S, Cusack S. Third-age education in Canada and Japan: attitudes toward aging and participation in learning. Educ Gerontol. 2006;32: 463-481.

19. Robbins-Ruszkowski JC. Challenging marginalization at the Universities of the Third Age in Poland. Anthropol. Aging Quart. 2013;34(2): $157-169$.

20. Wilińska M. Is there a place for an ageing subject? Stories of ageing at the University of the Third Age in Poland. Sociology. 2012;46(2): 290-305.

21. Barthalos I, Bognár J, Fügedi B, Plachy JK, Ihász F. Physical performance, body composition, and quality of life in elderly women from clubs for the retired and living in twilight homes. Biomed Hum Kinet. 2012;4:45-48.

22. Vagetti GC, Barbosa Filho VC, Moreira NB, de Oliveira V, Mazzardo O, de Campos W. Association between physical activity and quality of life in the elderly: a systematic review, 2000-2012. Rev Bras Psiquiatr. 2014;36:76-88.

23. Figueira HA, Figueira AA, Cader SA, et al. Effects of a physical activity governmental health programme on the quality of life of elderly people. Scand J Public Health. 2012;40:418-422.

24. Rikli RE, Jones CJ. Senior Fitness Test Manual. 2nd ed. Champaign, IL: Human Kinetics; 2013.

25. Quanjer PH, Tammeling GJ, Cotes JE, et al. Symbols, abbreviations and units. Working Party Standardization of Lung Function Tests. European Community for Steel and Coal. Eur Respir J Suppl. 1993;16: $85-100$. 
26. Quanjer PH, Tammeling GJ, Cotes JE, Pedersen OF Peslin R, Yernault JC. Lung volumes and forced ventilator flows. Work Group on Standardization of Respiratory Function Tests. European Community for Steel and Coal. Official position of the European Respiratory Society. Rev Mal Respir. 1994;11(3):5-40.

27. MLS Motor Performance Series [webpage on the Internet]. Schuhfried. Available from: http://www.schuhfried.com/viennatestsystem10/ tests-test-sets/all-tests-from-a-z/test/mls-motor-performance-series/. Accessed September 3, 2009.

28. Schoppe KJ. Das MLS-Gerät: ein neuer Testapparat zur Messung feinmotorischer Leistungen [MLS-Device: a new device for measurment of fine motor abilities]. Diagnostica. 1974;20:43-47. German.

29. Hamster W. Die motorische Leistungsserie - MLS [Motor Performance Series]. Dr G. Schuhfried, editor. Mödling, Austria: Handanwiesung; 1980. German.

30. Tobiasz-Adamczyk B, Brzyska M, Woźniak B, Kopacz MS. The current state and challenges for the future of health promotion in Polish older people. Int J Public Health. 2009;54:341-348.

31. Biernat E, Tomaszewski P. Socio-demographic and leisure activity determinants of physical activity of working Warsaw residents aged 60 to 69 years. J Hum Kinet. 2011;30:173-181.

32. Trost SG, Owen N, Bauman AE, Sallis JF, Brown W. Correlates of adults' participation in physical activity: review and update. Med Sci Sports Exerc. 2002;34(12):1996-2001.

33. Krems C, Luhrmann M, Neuhauser-Berthold M. Physical activity in young and elderly subjects. $J$ Sports Med Phys Fitness. 2004;44(1):71-76.

34. Ruuskanen JM, Ruoppila I. Physical activity and psychological well-being among people aged 65 to 84 years. Age Ageing. 1995;24: 292-296.

35. Owen N, Bauman A, Brown W. Too much sitting: a novel and important predictor of chronic disease risk? Br J Sports Med. 2009;43:81-83.

36. Hamilton MT, Hamilton DG, Zderic TW. Role of low energy expenditure and sitting in obesity, metabolic syndrome, type 2 diabetes, and cardiovascular disease. Diabetes. 2007;56:2655-2667.

37. Lord S, Chastin SF, McInnes L, Little L, Briggs P, Rochester L. Exploring patterns of daily physical and sedentary behaviour in community dwelling older adults. Age Ageing. 2011;40:205-210.

38. Keysor JJ. Does late-life physical activity or exercise present or minimize disablement? A critical review of scientific evidence. Prev Med. 2003;25(3):129-136.

39. McAuley E, Morris KS, Doerksen SE, et al. Effects of change in physical activity on physical function limitations in older women: mediating roles of physical function performance and self-efficacy. $J$ Am Geriatr Soc. 2007;55(12):1967-1973.

40. Spirduso WW, Cronin DL. Exercise dose-response effects on quality of life and independent living in older adults. Med Sci Sports Exerc. 2001;33:598-608.

41. Macera CA, Hootman JM, Sniezek JE. Major public health benefits of physical activity. Arthritis Rheum. 2003;40(1):122-128.

42. Myint PK, Smith RD, Luben RN, et al. Lifestyle behaviors and quality-adjusted life years in middle and older age. Age Ageing. 2011; 40:589-595.

43. Hamilton MT, Hamilton DG, Zderic TW. Exercise physiology versus inactivity physiology: an essential concept for understanding lipoprotein lipase regulation. Exerc Sport Sci Rev. 2004;32:161-166.

44. Holmberg AH, Johnella O, Nilsson PM, Nilsson J, Berglund G, Åkesson K. Risk factors for fragility fracture in middle age. A prospective population-based study of 33,000 men and women. Osteoporos Int. 2006;17:1065-1077.

45. Ahmad Shahla MD. Validity of bone mineral density and WHO fracture risk assessment thresholds in hip fractures. Arch Iran Med. 2011; 14(5):352-354.

46. Syed FA, Ng AC. The pathophysiology of the aging skeleton. Curr Osteoporos Rep. 2010;8:235-240.

47. Stenholm S, Alley D, Bandinelli S, et al. The effect of obesity with low muscle strength on decline in mobility in older persons: results from the InCHIANTI study. Int J Obes. 2009;33:635-644.
48. Zoico E, Di Francesco V, Guralnik JM, et al. Physical disability ad muscular strength in relation to obesity and different body composition indexes in a sample of healthy elderly women. Int $J$ Obes Relat Metab Disord. 2004;28:234-241.

49. Ribom EL, Mellstrom D, Ljunggren O, Karlsson MK. Population-based reference values of handgrip strength and functional tests of muscle strength and balance in men aged 70-80 years. Arch Gerontol Geriatr. 2011;53:114-117.

50. Rikli R, Jones CJ. Senior Fitness Test Manual. 2nd ed. Champaign, IL: Human Kinetics; 2013.

51. Forrest KY, Zmuda JM, Cauley JA. Correlates of decline in lower extremity performance in older women: a 10-year follow-up study. J Gerontol Ser A Biol Sci Med Sci. 2006;61(11):1194-1200.

52. Rikli R, Jones CJ. Development and validation of a functional fitness test for community-residing older adults. J Aging Phys Act. 1999; 7:129-161.

53. Onder G, Penninx BW, Lapuerta P, et al. Change in physical performance over time in older women: the Women's Health and Aging Study. J Gerontol Ser A Biol Sci Med Sci. 2002;57:289-293.

54. Toraman A, Yildirim N. The falling risk and physical fitness in older people. Arch Gerontol Geriatr. 2010;51:222-226.

55. Weiss EP, Spina RJ, Holloszy JO, Ehsani AA. Gender differences in the decline in aerobic capacity and its physiological determinants during the later decades of life. J Appl Physiol. 2006;101:938-944.

56. Ranganathan VK, Siemionow V, Sahgal V, Yue GH. Effects of aging on hand function. J Am Geriatr Soc. 2001;49:1478-1484.

57. Mattay VS, Fera F, Tessitore A, et al. Neurophysiological correlates of age-related changes in human motor function. Neurology. 2002; 58:630-635.

58. Laidlaw DH, Bilodeau M, Enoka RM. Steadiness is reduced and motor unit discharge is more variable in old adults. Muscle Nerve. 2000; 23:600-612

59. Wróblewska I, Błaszczuk J. The University of the Third Age as an institution stimulating elderly people - personal research. Nowiny Lekarskie. 2012;81(1):31-35.

60. Zdrodowska A, Wiszomirska J, Niemierzycka A, Czajkowska A, Magiera A, Słoń M. Physical fitness women over 60 years of age participating in the activities of the University of the Third Age. Postepy Rehabilitacji. 2012;3:19-25.

61. De Jong J, Lemmink KA, Stevens M, et al. Six-month effects of the Groningen active living model (GALM) on physical activity, health and fitness outcomes in sedentary and underactive older adults aged 55-65. Patient Educ Couns. 2006;62(1):132-141.

62. Kalisch T, Wilimzig C, Kleibel N, Tegenthoff M, Dinse HR. Agerelated attenuation of dominant hand superiority. PLoS One. 2006;1(1): e90. doi:10.1371/journal.pone.0000090.

63. Dik M, Deeg DJ, Visser M, Jonker C. Early life physical activity and cognition at old age. J Clin Exp Neuropsychol. 2003;25:643-653.

64. Weuve J, Kang JH, Manson JE, Breteler MM, Ware JH, Grodstein F. Physical activity, including walking, and cognitive function in older women. JAMA. 2004;92(12):1454-1461.

65. Tinetti ME, Baker DI, King M, et al. Effect of dissemination of evidence in reducing injuries from falls. $N$ Engl J Med. 2008;359:252-261.

66. Hatch J, Gill-Body KM, Portney LG. Determinants of balance confidence in community-dwelling elderly people. J Phys Ther. 2003; 83:1072-1079.

67. Yoon JJ, Yoon TS, Shin BM, Na EH. Factors affecting test results and standardized method in quiet standing balance evaluation. Ann Phys Rehabil Med. 2012;36(1):112-118.

68. Ball K, Timperio AF, Crawford DA. Understanding environmental influences on nutrition and physical activity behaviors: where should we look and what should we count? Int J Behav Nutr Phys Act. 2006;3:33. doi:10.1186/1479-5868-3-33.

69. Low G, Molzahn AE. Predictors of quality of life in old age: a crossvalidation study. Res Nurs Health. 2007;30(2):141-150. 
Clinical Interventions in Aging

\section{Publish your work in this journal}

Clinical Interventions in Aging is an international, peer-reviewed journal focusing on evidence-based reports on the value or lack thereof of treatments intended to prevent or delay the onset of maladaptive correlates of aging in human beings. This journal is indexed on PubMed Central, MedLine,

CAS, Scopus and the Elsevier Bibliographic databases. The manuscript management system is completely online and includes a very quick and fair peer-review system, which is all easy to use. Visit http://www.dovepress. $\mathrm{com} /$ testimonials.php to read real quotes from published authors.

Submit your manuscript here: http://www.dovepress.com/clinical-interventions-in-aging-journal 